\title{
An Actionist Approach to the Justificational Role of Perceptual Experience*
}

\author{
EROS MOREIRA DE CARVALHO**
}

\begin{abstract}
In this paper, I defend an account of how perceptual experience can bear rational relation to our empirical thought. In the first part, I elaborate two claims that are central for the justificational role of perceptual experience, namely, the claim that perception and belief share the same kind of content, and the claim that perception is independent from belief. At first sight, these claims seems not to be compatible, since the first one seems to require the truth of content conceptualism, while the second one seems to require its falsity. In the second part, based on Alva Noë's actionist theory of perception, I argue in favor of a less intellectualist interpretation of the first claim, uncommitted to content conceptualism, and then I show how it can be reconciled with the second claim. Finally, I explain how perception holds rational relationships with our empirical thought through the exercise of observational concepts. These concepts link what I propose to call 'space of actions' to the logical space of reasons.
\end{abstract}

Keywords: Alva Noë, cognitive penetrability, conceptualism, internalism, perceptual justification, sensorimotor theories of perception.

\section{Introduction}

7 he debate regarding the nature of the content of perceptual experience has assumed new forms over recent decades with the introduction of the question of whether this content is conceptual or non-conceptual. ${ }^{1}$ This metaphysical question about the nature of perception is generally

* Acknowledgements: this work was supported by CNPq (Conselho Nacional de Desenvolvimento Científico e Tecnológico) Foundation (Brazil).

** $\quad$ Universidade Federal do Rio Grande do Sul - CNPq. $\triangle$ eros.carvalho@ufrgs.br

1. The idea that perceptual experience contains non-conceptual content was initially introduced by Gareth Evans. He claims that our mental structure has two systems, the informational and the cognitive, the sub-personal and the personal, respectively. Perception and memory are part of the informational system. A function of the first, for example, is providing the cognitive system with information about the surrounding environment. On the other hand, thought and the ability to judge are part of the cognitive system. One of the reasons for Evans' defense of the notion that perception contains non-conceptual content is that he holds perception to be separate from belief. Later, we will discuss whether this hypothesis excludes any form of conceptualism. See Gareth Evans, The Varieties of Reference (Oxford: Clarendon Press, 1982), 123-24.

Provided for Personal License use. Not for reproduction, distribution, or commercial use. ㄷ 2016 Revista Portuguesa de Filosofia. All Rights Reserved. 
posed by another, which is of an epistemic character: how can perceptual experience justify beliefs about our surroundings? John McDowell holds that if experience does not already have conceptual content to present the world as being a certain way, thus leading to a shared link between perception and thought, then it is difficult to see how experience could justify a belief, ${ }^{2}$ especially if we, like McDowell, understand justification in internalist terms. In opposition to this position, Athanassios Raftopoulos claims that if perceptual experience intrinsically involves concepts and, therefore, is cognitively penetrated, then experience is not independent of our deeply held beliefs; and, as a result, it cannot operate as an impartial court for justification, ${ }^{3}$ since the supporting evidence provided by experience is epistemologically biased by our own beliefs. ${ }^{4}$

In this paper, I defend an account of how perceptual experience holds a rational relation with empirical thought. In the first part, I will elaborate two claims that seem central to explaining the justificational role of perceptual experience, namely, the claim that perception and belief share the same kind of content, and the claim that perception is independent from belief. I show how difficult it is to reconcile these claims. The first one seems to require the content view of conceptualism, while the second one seems to imply its rejection. I argue that John McDowell fails in doing justice to the second claim in Mind and World, although he thinks otherwise. In the second part, based on Alva Noë's actionist theory of perception, I support a less intellectualist reading of the first claim, uncommitted to the content conceptualism, and show how it can be reconciled with the second claim. Finally, I explain how perception holds rational relationships with our empirical thought through the exercise of observational concepts. These concepts, being learned at the interface between perception and cognition, connect what I propose to call 'space of actions' to the logical space of reasons. This actionist approach to the justificational role of perceptual experience is intended to doing justice to internalism.

2. John McDowell, Mind and World (Massachusetts: Harvard University Press, 1996), 52-3.

3. Athanassios Raftopoulos, "The Cognitive Impenetrability of Perception and TheoryLadenness," Journal for General Philosophy of Science 46, (2015): 91.

4. Susan Siegel provides the following example: suppose that $\mathrm{S}$ believes, for no good reason, that $\mathrm{R}$ is upset with her. Upon meeting $\mathrm{R}$, due to her belief, $\mathrm{S}$ sees $\mathrm{R}$ as being upset with her. Based on her experience, $\mathrm{S}$ believes even more firmly that $\mathrm{R}$ is upset with her. See Susan SiEgEL, "Cognitive penetrability and perceptual justification," Noûs 46, no. 2 (2012): 210.

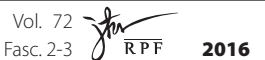

Provided for Personal License use. Not for reproduction, distribution, or commercial use. (C) 2016 Revista Portuguesa de Filosofia. All Rights Reserved. 


\section{Preliminary Considerations}

Since Heck, ${ }^{5}$ it is common to distinguish between two versions of conceptualism: the state view and the content view. The first is a thesis about representational states or vehicles, and maintains that for a mental state to carry the representation of a state of things, of an object, or of a property, the subject of this mental state must have the concepts required to specify this state of things, this object, or this property. ${ }^{6}$ The non-conceptualist claims that perceptual states can carry representation without the subject of these states possessing the concepts required for specifying the content of this representation. The second is a thesis about the content of the representations, which is the intentional object of a representation. The content conceptualist claims that the content of mental representations is or can be articulated conceptually, i.e., the content of a perception is propositionally structured. The non-conceptualist claims that there is or can be perceptual content that is not conceptually articulated or not even articulable conceptually. The state non-conceptualist does not need to commit to the non-conceptualism of content, but the reverse does not seem possible. Note that to the state non-conceptualist, the content of a representation can be shared by conceptual and non-conceptual representations; perceptions and beliefs can have the same type of content, even if the states differ in relation to dependence on the possession of concepts.

\section{The shared content and the problem of the intelligible interface}

To prevent empirical thought from being represented "as a frictionless spinning in a void", ${ }^{7}$ we must have a concept of experience that enables our empirical beliefs to be responsive to the world. In essence, for the world to constrain our empirical beliefs, experience must present it as being a certain way and accessible to thought. This seems to require that there be something in common between the way we think about the world and the way that experience presents the world to us. This would be the

5. Richard Heck, "Nonconceptual content and the space of reasons," The Philosophical Review 109, (2000): 483-523.

6. The state view may be weakened by requiring only that the subject have the capability to acquire the concepts necessary for specifying the content of representation.

7. John McDowell, Mind and World, 11.

$$
\text { Fasc. } 2-32 \text { ford } 2016
$$

Provided for Personal License use. Not for reproduction, distribution, or commercial use. (C) 2016 Revista Portuguesa de Filosofia. All Rights Reserved. 
shared content thesis, which recurrently appears in the literature on the topic:

it is only because experience involves capacities belonging to spontaneity that we can understand experience as awareness, or apparent awareness, of aspects of the world at all. ${ }^{8}$

judgments and experience can diverge and even contradict one another. But to say that they can be in conflict is to say that it can be in accord; and this would seem to show that they have the same sort of content. ${ }^{9}$

For the one major virtue of thinking of perceptions as propositional attitudes is that it makes it easy to see how they might intelligibly interface, in virtue of their contents, with other states of mind. ${ }^{10}$

The shared content thesis captures two requirements, one weaker, and the other stronger, which seem central to the justificational role of perceptual experience. First, that which experience presents to us must be able to point to the truth or falsehood of our empirical beliefs. In this sense, experience and thought can be directed to the same things. Second, whatever experience presents to us, it must do so intelligibly, i.e., in a way that enables recognition or understanding of the relevance of what is perceptually presented to the truth of what is thought or believed.

The first requirement claims that there must be a truth-indicating relationship between a perceptual state and a belief if the former, due to its content, justifies the latter. The truth conditions of the belief must be partially or completely satisfied by what is presented to us perceptually. If our perceptual beliefs deal with facts or events that are witnessed, and with surrounding three-dimensional objects and their properties, then the first requirement favors a conception of experiences according to which facts and objects are presented to us perceptually. Otherwise, as in the case of a sense-data theory of experience, in order to satisfy the first requirement, we would have to either show how facts and objects are constructed from sensations or establish principles that connect sensations to the distal objects or occurrences that caused them. I make the assumption that our ordinary perceptual beliefs deal with events and the surrounding three-dimensional objects. The first requirement alone is not

\section{Ibid., 47.}

9. Alva Nö̈, Action in Perception (Massachusetts: MIT Press, 2006), 189.

10. Daniel Hutтo, and Erik Myr, Radicalizing Enactivism: Basic minds without content (Cambridge, MA: MIT Press, 2013), 103, emphasis ours.

$$
\text { Fasc. } 2-32 \text { for } \overline{\text { RPF }} 2016
$$

Provided for Personal License use. Not for reproduction, distribution, or commercial use. (C) 2016 Revista Portuguesa de Filosofia. All Rights Reserved. 
sufficient for requiring the state view and only perhaps the content view if we assume that the content of beliefs is articulated conceptually. For perceptual experience to be among the relata of the truth-indicating relationship, it is sufficient that the content of a perceptual state can also be the content of a belief. It does not matter that perception and belief are different kinds of mental states. Only the content non-conceptualist would have some hard time explaining the truth-indicating relationship under the assumption that the content of beliefs is articulated conceptually. ${ }^{11}$

Conceptualism takes on a more attractive position in the epistemological debate when we consider the second requirement. It holds that there must be a rational relation between a perceptual state and a belief if the former, due to its content, justifies the latter. Experience must constrain our attitude regarding a proposition rationally, rather than just causally. Therefore, the subject must be capable of recognizing the relevance of what experience presents to the truth of the proposition considered. It is easy to understand how this recognition is possible if our conceptual abilities are already operating in perceptual experience. If experience, for example, delivers an object from the field of vision as a notebook then, due to the inferential connections that the concept of notebook has with others, the subject can recognize the relevance of this experience to the truth of the proposition that there is a notebook, that electronic equipment is present, or that this object is not an animal, etc. That experience presents us with an object in a manner that can be retrieved in a series of thoughts about the object makes the normative relationship between experience and belief intelligible, since it explains how the subject can, if it were sensitive to the inferential connections of the concepts operating in experience, adopt a rational attitude in relation to the proposition considered. This is why McDowell claims that concepts must already be operating in experience. Otherwise, as Sellars had already pointed out, we find ourselves committed to the myth of the given, ${ }^{12}$ or, as Hutto and Myin point out, we make the rational relationship between experience and propositional attitudes mysterious, which creates the problem of the intelligible inter-

11. It is not trivial that the content of beliefs and propositional attitudes are conceptually articulated. STALNAKER, for example, maintains that the content of beliefs and perceptual states must be individualized by means of classes of possible worlds. To him, the conceptualist debate is only valid in relation to representational states or vehicles. See Robert Stalnaker, "What might nonconceptual content be?," Philosophical Issues 9, (1998): 339-352.

12. Wilfrid Sellars, "Empiricism and the Philosophy of Mind," in Science, Perception and Reality (London: Routledge \& Kegan Paul, 1963), 127-196.

$$
\text { Fasc. } 72-3 \text { fot } \overline{\text { RPF }} 2016
$$

Provided for Personal License use. Not for reproduction, distribution, or commercial use. (C) 2016 Revista Portuguesa de Filosofia. All Rights Reserved. 
face. ${ }^{13}$ Thus, a perceptual experience justifies a belief not just when there is a truth-indicating relationship between them but also a rational relationship; the subject must acknowledge the relevance of the content of her experience for the truth of the proposition considered. Moreover, this acknowledgment seems to require that the subject be able to think the judgment that the content of the perceptual experience is relevant to the truth of the considered proposition, which, in turn, seems to require that experiences have propositional content. The relevance at issue is noted by the subject by means of the inferential connections of the concepts that figure in the propositional content of experience and of the proposition considered. Thus, content conceptualism seems to be necessary to properly explain the justificational role of perceptual experience.

The conceptualist position can sound very intellectualist, and it must sound so if we assume that the concepts are actively operating in experience, i.e., just as they are operating when we deliberate. However, McDowell, as early as in Mind and World, claims that concepts are operating passively in perception. ${ }^{14}$ It is not quite clear what he means by this. In a negative sense, it at least means that a perceptual episode does not involve the reflexive application of concepts; it only involves the current operation of concepts: "having things appear to one a certain way is already itself a mode of actual operation of conceptual capacities". ${ }^{15}$ Even so, McDowell's position would be intellectualist enough by not attributing a normative role to the experience of creatures that lack the appropriate concepts or by suspending the normative role of the experiences of creatures that, for some reason, do not passively put into operation the appropriate conceptual abilities in perceptual experience. ${ }^{16}$

13. Daniel Hutтo, and Erick Mrin, Radicalizing Enactivism: Basic minds without content, 104.

14. John McDowelL, Mind and World, 62.

15. Ibid., 62. The fact that in Mind and World McDowell does not discuss in greater detail the passive operating of concepts in experience casts a shadow over how well his position meets the second requirement discussed above. How does the passive application of concepts solve the problem of the interface and explain the acknowledgment of the relevance of the content of experience for a considered proposition? If the passive application of concepts were automatic and executed through sub-personal mechanisms, it is not clear how it would involve or implicate the recognition referred to.

16. In more recent articles, McDowell has substantially weakened his conceptualist position, to the point of no longer requiring concepts to be in operation in the perceptive act itself. Due to space constraints, we will not compare his more recent position with the one I will develop based on NoË's theory of perception. See John McDowelL,

"Avoiding the Myth of the Given," in Having the World in View (Massachusetts: Harvard

$$
\text { Vol. } 72 \text { Fasc. } 2-3 \text { tor } 2016
$$

Provided for Personal License use. Not for reproduction, distribution, or commercial use. (C) 2016 Revista Portuguesa de Filosofia. All Rights Reserved. 
An externalist in terms of the justification can easily avoid the intellectualist disadvantage by setting aside the second requirement. However, she has to face the challenge of showing how her concept of justification is relevant to our understanding of epistemic agency. I do not intend to support the internalist views of justification in opposition to the externalist ones in this paper. My narrower aim is to show that it is possible to defend a minimally internalist view of justification that is compatible with the thesis of independence and that has no undesirable intellectualist consequences.

\section{The independence of perception in relation to belief and the problem of cognitive penetrability}

If we had reasons to believe that the way that perceptual experience presents the world to us is itself determined by our beliefs or by any other higher cognitive states, then we would have to reject that perceptual experience can improve the epistemic quality of our beliefs. Following Susan Siegel's formulation for cognitive penetrability, if two persons who are aware of the same region of space and being bombarded by the same distal stimulus have perceptions with different content and relevantly different beliefs or superior cognitive states, then these superior cognitive states are causally responsible for the content of these perceptual states ${ }^{17}$ Cognitively penetrated experience seems to imply a vicious circle; therefore, although it does not bar the possibility that experience can rationally support a belief, it creates an obstacle for our thinking that it increases the epistemic authority of the belief supported by an experience of this kind. Consequently, it is reasonable to defend that the justificational role of

University Press, 2013), 256-274.

17. Susana SiEgel, "Cognitive Penetrability and Perceptual Justification," 207. It is worth noting that the relevant causal influence for characterizing the cognitive penetrability should be one that acts upon the content of the experience. It is possible to accept, and there is empirical evidence for accepting, pre-perceptual causal influence (i.e., beliefs and expectations that causally determine where to drive the focus of our attention) and post-perceptual influence (i.e., beliefs and expectations that causally determine the exercise of recognition skills on the perceptions previously delivered by the perceptual system). These cases of causal influence do not threaten the epistemological role of perceptual experience. See Athanassios RAFTOPOulos, "The Cognitive Impenetrability of Perception and Theory-Ladenness," 91, and Zenon Pylyshyn, Seeing and Visualizing: It's Not What You Think (Massachusetts: MIT Press, 2003), 79-85.

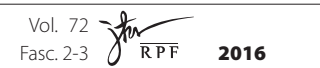

Provided for Personal License use. Not for reproduction, distribution, or commercial use. (C) 2016 Revista Portuguesa de Filosofia. All Rights Reserved. 
perceptual experience also depends on the independence of perception in relation to belief ${ }^{18}$ :

because the way one sees the world is largely independent of one's theoretical attachments, it is possible to see that the predictions - even of theories that one likes a lot - aren't coming out. ${ }^{19}$

Nor is the case that, when one has a visual experience, say, one must even be inclined to judge things to be the way the experience presents them as being. Experience is belief-independent $[. ..] .^{20}$

If what one sees depends on what one believes, people with different commitments see different worlds. And if there is no neutral basis on which matters of meaning could be resolved, how could these people communicate? ${ }^{21}$

Basically, the independence claim captures the requirement that perceptual experience present the world as it really is, so that it may act as a court for our empirical beliefs. What we must investigate is whether the independence thesis is incompatible with the conceptualism required by the shared content claim. If it is, then the dilemma introduced at the beginning of this article is inevitable, and the minimal internalism that I am trying to articulate is simply not feasible.

In the previous section, I highlighted that the shared content claim, according to a reading on how experience can rationally constrain empirical thought, requires the truth of content conceptualism. When the concepts are operating within a judgment, other cognitive states rationally constrain the application of these concepts due to their inferential connections. For example, if I am looking at a mug that seems red to me and I consider the proposition that it is red, I can abstain from applying the concept of red to the mug if I am informed that the environment I am

18. A second reason why experience is independent from belief is that in contexts where it is called upon for deciding between competing theories, its content must be neutral in relation to the competing theories, i.e., the scientist's commitment to one theory or another must not cognitively penetrate the experiences that will serve as testimony for deciding the debate between competing theories, since, otherwise, we would have a clear case of bias. See Jery Fodor, "Burge on Perception," in The Conceptual Mind: New Directions in the Study of Concepts, eds. Eric Marglils, and Stephen Laurence (Massachusetts: MIT Press, 2015), 24.

19. Jery Fodor, "Burge on Perception," 42.

20. Alva NoË, Action in Perception, 188.

21. Athanassios Raftopoulos, "The Cognitive Impenetrability of Perception and TheoryLadenness," 91.

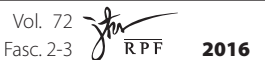

Provided for Personal License use. Not for reproduction, distribution, or commercial use. (C) 2016 Revista Portuguesa de Filosofia. All Rights Reserved. 
in is full of red light. In fact, the very nature of belief is that it should be under rational control and, therefore, sensitive to the individual's other cognitive states. ${ }^{22}$ It is to be expected that the content of a judgment is cognitively penetrate, i.e., that the content of other cognitive states rationally constrains and, as a result, causally determines the content of the belief formed. If this were the model for how concepts passively operate in perceptual experience, then it would be difficult to deny the conclusion that experience is cognitively penetrated.

In discussing Gareth Evans's argument for the claim that perception is independent from belief, McDowell accepts Evans's criticism that the model of active operating of the concepts is unsuitable for understanding perception. ${ }^{23}$ This model is inadequate even from a phenomenological standpoint. It would be wrong to construe McDowell as suggesting that conceptual capabilities actively operate in perception, just as occurs in a deliberate judgment. Thus, McDowell seems to think that his position is not incompatible with the claim that perception is independent from belief if we consider that the conceptual capacities passively operate on experience. ${ }^{24}$ At least, in this case, there would not be influence from beliefs brought to awareness, as occurs in a deliberate judgment. However, it is not clear that there would be no cognitive influence on the determination of perceptual content, even in this way. Even assuming that the function of conceptual capabilities in perception is passive and unconscious, if they share the same inferential structure as the capabilities that actively operate in judging, then there is no surprise in the fact that information and beliefs stored in long-term memory can influence the determination of the content of the perceptual experience. Whether this influence is conscious or not bears no relevance on cognitive penetrability. McDowell does not seem to foresee this possibility, since he does not provide an answer for it.

Another possibility would be to maintain that perception can involve concepts in a way that would not imply that experience is cognitively penetrated. This possibility could be realized by encapsulated concepts, i.e., concepts that are not inferentially connected to the concepts we actively use for deliberating. If it were possible to conceive of a group of representational structures similar to the concepts that figure in thoughts, yet are

22. John McDowelL, Mind and World, 60.

23. Ibid., 61.

24. Ibid., 62 .

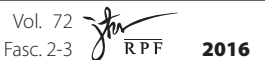

Provided for Personal License use. Not for reproduction, distribution, or commercial use. (C) 2016 Revista Portuguesa de Filosofia. All Rights Reserved. 
not available for reflection-i.e., these structures cannot figure in thoughts or beliefs and also cannot be used to access any content from long-term memory-then these structures could compose perceptual representations without undermining the claim that perception is independent from belief. Both Pylyshyn and, more recently, Fodor flirt with this possibility. The former claims that the perceptual system could work with a proprietary vocabulary to represent such "perceived properties as which regions of a scene go together as a single object, which contours go with which surfaces, which surfaces partially occlude other surfaces, and so on". ${ }^{25}$ The latter highlights that he does not see any reason for such general representations not to be taken as concepts: "why, in particular, shouldn't mental representations that would be constituents of thoughts but for the constraints that a modular cognitive architecture imposes be good enough to qualify as concepts?". ${ }^{26}$

The question of what concepts are is a difficult one, and I do not intend to provide an answer to it in this article; however, more about the issue will be discussed later. McDowell would say that Fodor's invocation of the concepts is "mere word-play". ${ }^{27}$ Capabilities that are not potentially under the individual's rational control cannot be genuinely understood as conceptual. A second reason for McDowell to reject the possibility contemplated by Fodor and Pylyshyn is his concern that experience can rationally constrain empirical thought. Thus, the concepts that operate passively in experience have to be the same as those that operate actively in thought and in judgment, since, as we observed above, they mediate the inferential connections that enable the subject to recognize the relevance of the content of experience to the truth of a considered proposition. Thus, we either aggravate the interface problem if, according to Fodor and Pylyshyn, we embrace the independence thesis in a manner that disallows that the concepts operating passively in the experience can be the same as that we use in active thought, or we live together with a threat of cognitive penetrability in experience if, like McDowell, we embrace the shared content thesis as he understands it in Mind and World. Once again, the dilemma from where we started.

The solution to this dilemma that I will explore is as follows. The shared content thesis involves the requirement that experience rationally

25. Zenon Pylyshyn, Seeing and Visualizing: It's Not What You Think, 66.

26. Jery FODOR, “Burge on Perception," 213.

27. John McDowelL, Mind and World, 62.

$$
\text { Fasc. } 2-32 \text { fors } 2016
$$

Provided for Personal License use. Not for reproduction, distribution, or commercial use. (C) 2016 Revista Portuguesa de Filosofia. All Rights Reserved. 
onstrains empirical thought. In other words, we have to understand how the subject can recognize the relevance of the perceptual content for a proposition considered. Content conceptualism explains how this recognition is possible through inferential relations mediated by the concepts that would figure in the very content of experience and beliefs. This is not the only explanation possible, as I intend to show. I believe that Noë's actionist theory of perception ${ }^{28}$ supplies us with elements for developing an explanation for this recognition that commits itself to, at best, state conceptualism, which will allow me to show how it is possible to simultaneously support the shared content and the independence claims.

\section{Conceptualism and the actionist theory of perception}

In Action in Perception, Noë does not deny that perception is independent from belief; what he denies is that the acceptance of this claim creates an obstacle to embracing conceptualism. ${ }^{29} \mathrm{He}$ acknowledges that perception can be in disagreement with judgment, such as in illusion situations. In the excerpt cited in the third section above, he draws attention to its ability to disagree as the precise basis for perception's relevance for judgment, noting that, similar to how they can disagree, they can also agree with each other. Noë then reminds us of something we have already mentioned: for perceptual content to be relevant to empirical thought and be able to enter into agreement or disagreement with it, perception must present the world to us as being a certain way. Moreover, the subject must be able to understand this content. Noë then claims that,

one reason to think that perceptual experience is conceptual is that experience presents things to one as being this way or that; one needs an understanding of the ways experiences is presented as being. ${ }^{30}$

Noë's concern is to ensure that the things that we perceive or that are presented to us by experience can also be things about which we form

28. In Action in Perception, Noë uses the term "enactive" and other cognates to qualify his theory, but he has recently started to use "actionist" and its cognates. See Alva Nö̈, "Conceptual Pluralism, Direct Perception, and the Fragility of Presence," in Open MIND: 27(T), eds. Thomas Metzinger, and Jennifer Windt, 1-15. Frankfurt am Main: MIND Group, 2015.

29. Alva NoË, Action in Perception, 188.

30. Ibid., 189.

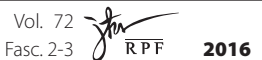

Provided for Personal License use. Not for reproduction, distribution, or commercial use. (C) 2016 Revista Portuguesa de Filosofia. All Rights Reserved. 
beliefs and have thoughts, since, without this, we would not understand how perception could agree or disagree with judgment. We have already seen how this kind of consideration led McDowell to support content conceptualism in Mind and World. Noë's case seems different due to both the view of the concept that he proposes and the theory of perception that he sustains. I am going to briefly introduce his actionist theory of perception and argue that it requires only state conceptualism, which in turn is sufficient for supporting the shared content claim. I do not intend to defend Noë's theory here, but rather to show how it can provide a good basis for developing an explanation for the justificational role of perceptual experience.

The main claim of his theory is that perception is a way of acting, or, as he stated more recently, "perception is the activity of exploring the environment making use of knowledge of sensorimotor contingencies". ${ }^{31}$ To Noë, it is impossible to dissociate perception from the sensorimotor skills that allow us to move and interact with the world. Perceiving, he states, "is understanding the effect of movement on sensory stimulation". ${ }^{2}$ It is not just a matter of noting that perception causally depends on sensorimotor skills, but rather that perceptual content itself is constituted by these skills. ${ }^{33}$ Without them, an individual would not be capable of understanding her sensory stimulus and, therefore, would not perceive anything at all. For example, that we perceive a tomato as being voluminous and three-dimensional, despite only being able to place one of its sides in our field of vision at any one time, is explained by the implicit understanding of how the tomato would seem if we moved in relation to it, i.e., by the implicit understanding of the dependence that the flow of sensations has on motor activity. This sensorimotor knowledge constitutes, therefore, the three-dimensional and voluminous aspect of the tomato that experience provides us with. In Noë’s words,

You visually experience parts of the tomato that, strictly speaking, you do not see, because you understand, implicitly, that your sensory relation to those parts is mediated by familiar patterns of sensorimotor dependence. $^{34}$

31. Alva NoË, "Conceptual Pluralism, Direct Perception, and the Fragility of Presence," 1.

32. Alva Nö̈, Action in Perception, 1.

33. Ibid., 2 .

34. Ibid., 77.

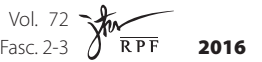

Provided for Personal License use. Not for reproduction, distribution, or commercial use. (C) 2016 Revista Portuguesa de Filosofia. All Rights Reserved. 
The sensorimotor skills are thus essential for a subject to be able to understand her own sensory stimulus, without which the surrounding world itself would not be presented experientially. Another example is the way that we see a plate as being circular from an oblique angle, even though it looks elliptical. The plate's circularity is provided to us through experience, due to the implicit understanding of how the plate would appear to us as we assume different positions in relation to it; we implicitly understand "the transformations the elliptical apparent shape (aspect) would undergo as we move." 35 This understanding is constituted by the sensorimotor skills that mediate our interactions with the plate and movements in relation to it. The appearance of an object from a particular position is not merely given to us; it also depends on sensorimotor skills in order to be understood. Understanding the elliptical appearance of the circular plate as seen from a certain position involves understanding that this appearance depends on the spatial relationship that we have with the plate, that it would stop or change if we moved or inclined our head, and that, for example, we would have to move our hand in a certain way to gasp the plate (if it were in reach), different from the way we would move our hand if the circular plate were in the center of our field of vision. Thus, from the bottom up, we can say that the appearance of an object becomes more intelligible to the extent that it connects to body's actions directed at this object from a particular position, such as holding, pushing, approaching the object, and so on. One of the object's properties, in turnsuch as the circularity of the plate or the tomato's voluminous quality-is given to us by perception according to how a series of appearances of an object is collected, explored, and connected by sensorimotor skills carried out as we move in relation to that object. As Noë observed, "our grasp of the plate's sensorimotor profile makes its shape available in experience." 36 Action is constitutive of the content of perception to the extent that the sensory content of an experience is invested with spatial content by means of sensorimotor skills. Without these skills, effectively no object would be given to us in space. ${ }^{37}$

Noë proposes that we consider these sensorimotor skills as conceptual or proto-conceptual. ${ }^{38} \mathrm{He}$ presents two reasons for this

\footnotetext{
35. Ibid., 78 .

36. Ibid., 79 .

37. Ibid., 95.

38. Ibid., 199.
}

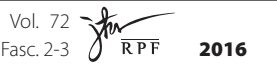

Provided for Personal License use. Not for reproduction, distribution, or commercial use. C 2016 Revista Portuguesa de Filosofia. All Rights Reserved. 
proposal. The first is based on criticism that he presents regarding the understanding of acquiring concepts based on the model for explicit deliberate judgment. According to this model, the possesion a concept depends on the knowledge and ability to represent the criterion to apply this concept. This requirement is highly intellectualist and makes it difficult to explain not only the behavior of children but even that of adults. For example, someone can reliably recognize instances of modus ponens without knowing how to articulate the reason why modus ponens is a valid argument. That is, someone can be able to recognize an argument as being valid without knowing to express the reason why it is valid. It would be reasonable to say that this person possesses both the concept of modus ponens and that of validity, even though she is not able to explicitly represent the criteria that govern the application of these concepts. Daily practice that is sensitive to instances of modus ponens as legitimate arguments is enough to attribute the concept of modus ponens to the individual, even if the subject does not have a term for it or does not know how to articulate the criteria for its application. Thus, the possession of a concept must, according to Noë, be understood as the possession of some practical skills, and "some practical skills - some sensorimotor skills - are simple concepts, or so I propose." 39

The second reason for Noë's proposal is based on his commitment to the shared content claim. Noë states that perceptual experience must present the world as being a certain way, and that the subject must have an understanding of the way that the world is presented through experience if we desire to uphold the fact that experience can agree or disagree with empirical thought. In Noë's theory, this understanding is enabled by sensorimotor skills. Without them, as we observed above, the subject would not be able to understand her own sensations. If we understand that these skills are conceptual, then the way that perceptual experience presents the world to us would also be conceptual. If sensorimotor skills are conceptual and necessary for the subject to understand her sensations, then possessing concepts is essential to having perceptual experiences. Thus, Noë's theory of perception is conceptualist from the outset. I do not believe that Noë needs to commit to the content view; arguably, state view is sufficient and compatible with his claims. Sensorimotor skills of a certain type are necessary for the subject to have a perceptual state with certain content, for example, a perceptual state where the voluminous

39. Ibid., 199.

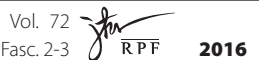

Provided for Personal License use. Not for reproduction, distribution, or commercial use. (C) 2016 Revista Portuguesa de Filosofia. All Rights Reserved. 
aspect of the tomato is presented. The burden of proof lies with showing how the state view faces the interface problem. Without the content view, we can no longer appeal to the inferential connections to explain the justificational role of experience. I will address this difficulty later, but we must first evaluate Noë's proposal of considering sensorimotor skills as conceptual skills.

The question that the non-conceptualist can raise is whether Noë is correct in considering sensorimotor skills to be conceptual. Regarding his first motivation, we previously said that Noë criticizes the understanding of the possession of concepts by means of the explicit deliberate judgment model. Someone acquires a concept and learns to apply it correctly in different situations; similarly, someone acquires the skill of seeing the voluminous aspect of the tomato and assimilates the appropriate sensorimotor contingencies. In both cases, it is not necessary for the subject to be able to respectively represent the criteria that govern the application of the concept and the skills that incorporate these contingencies. It seems that this requirement for reflexiveness, made by the explicit deliberative judgment model, is in fact very intellectualist and rigorous, and if we dismiss this requirement, the convergence of sensorimotor skills and conceptual skills will not seem inadequate. However, this model sets another requirement that creates an obstacle for Noë's analogy. Thoughts, whether they are explicit or not, are connected to each other, which means that we do not attribute to a subject the ability to formulate and entertain a certain proposition if the subject were not sensitive to the fact that the truth or falsehood of this proposition rationally constrains her to accept or reject other propositions. Someone who finds chocolate tasty must also find that it is edible. If a subject agrees to a statement expressing the first judgment and dissents to another expressing the second, we must conclude that either this subject did not understand the statements at issue, or she is unable to entertain and formulate the judgments at issue. This phenomenon of connection between thoughts and judgments is usually explained by the compositional nature of thought, i.e., by the fact that it is constituted by representational structures that satisfy Evans's generality constraint. ${ }^{40}$ In this model, concepts are the very representations that

40. According to Evans, our thoughts are structured by general representations that can be combined and recombined to form different thoughts. The thought that $a$ is $F$ is at the intersection of two series of thought: the series $a$ is $F$, $a$ is $G$, $a$ is $H$, etc., and the series $a$ is $F, b$ is $F, c$ is $F$, etc. A subject would thus be able to have the thought that $a$ is $F$ only if he had the ability to represent $a$ under other predicates that he possesses

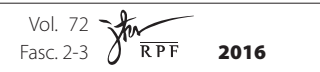

Provided for Personal License use. Not for reproduction, distribution, or commercial use. C 2016 Revista Portuguesa de Filosofia. All Rights Reserved. 
compose thoughts or are skills that enable us to have representations that compose thoughts. Noë's analogy is thus weakened, since sensorimotor skills are not general, nor do they enter systematic relationships with one another to form other skills. The sensorimotor skill that enables someone to experience the voluminous aspect of apples when she has an apple in her vision field does not extend itself automatically to experiencing the voluminous aspect of other objects, since different objects will demand the assimilation of different sensorimotor contingencies. In fact, this skill does not even extend itself to experiencing the voluminous aspect of apples under any circumstance. If the environment is very dark, or too bright, or filled with dense fog, or if something suddenly conceals the apple, the skill at issue is not able to present us with the apple's voluminous aspect. Thus, sensorimotor skills neither compose, nor are they general: rather, they are strongly dependent on context. Philosophers and psychologists who consider compositionality and generality as necessary traits of concepts will, thus, tend to reject Noë's proposal. ${ }^{41}$

A strategy favorable to Noë would be to weaken the requirement for generality that is imposed on the concepts. ${ }^{42}$ Another would be to appeal

and the ability to represent $F$ applied to other individuals that he is able to conceive. Concepts in this approach would be nothing more than the general representations required for explaining the systemic compositionality of thoughts. See Gareth Evans, The Varieties of Reference, 100.

41. It is worth citing Evans once again. Precisely for understanding that concepts compose and that certain audio stimuli gain spatial content due to the connection with body movements, Evans, unlike Noë, draws the conclusion that the perceptual information system carries and manipulates non-conceptual content: "we can say, then, that auditory input $[\ldots]$ acquires a (non-conceptual) spatial content for an organism by being linked with behavioral output in, presumably, advantageous way." See Gareth Evans, The Varieties of Reference, 156.

42. Noë himself appeals to the behavioral evidence of baboons that permitted the attribution of the following type of inference: $S$ has a high social status in the group and $R$ belongs to $S$ 's family or subgroup, so $R$ also has a high social status in the group. See Alva NoË, Action in Perception, 185-187. Elizabeth Camp reports that behavioral evidence of a change in the social status of a baboon can make many others in the same family also lose social status and be treated accordingly, which would also be better explained by attributing minimal inferential skills to the baboons. This baboon probably lacks such general and structured conceptual skills as ours, yet he must have them to some degree. It could be that their ability to think about social hierarchies does not go beyond their conspecifics or even beyond their own group. In this sense, their conceptual skills would create context-dependent representations, but even so they would not stop being compositional. See Elizabeth CAMP, "A language of baboon thought," in The Philosophy of Animal Minds, ed. Robert LuRz (New York: Cambridge University Press, 2009), 112

$$
\text { Vol. } 72 \text { fosc. } 2-3 \text { tor } 2016
$$

Provided for Personal License use. Not for reproduction, distribution, or commercial use. (C) 2016 Revista Portuguesa de Filosofia. All Rights Reserved. 
to cognitive phenomena that do not involve compositionality and that could be fruitfully explained by referring to the possession of practical skills of the kind that Noë understands as being concepts. ${ }^{43}$ However, I will not explore these strategies. As I have already stated, I do not intend to offer a solution to the concept's problem. Below, I present Noë's most recent position on the topic, and I will then address the central epistemological question of this article.

Given the difficulty in reconciling into a single model the sensorimotor skills-which are context-dependent and not compositional-and the skills involved in deliberative judgment-which are compositional and general-Noë recently proposed a pluralist approach in relation to the nature of the concepts, unified only by a functional characterization of them. Concepts must be understood as skills of access, i.e., "concepts, I propose, should be thought of as techniques of enabling access to what there is" "44,"they are rather skills for taking hold of what there is" 45 , and there are different modes of access, each of them conferring a different way of understanding what is there. Noë distinguishes at least three modes of access or understanding: the perceptual mode, the active mode, and the judgmental mode. Each of these modes involves cooperation and the performance of different techniques and skills through which we keep in touch with what is there and carry out different tasks with what exists. These modes of access and understanding, although they could be related,

43. Some psychologists distinguish perceptual categories from conceptual categories, stating that this distinction captures the contrast between knowing what something looks like and knowing what something is, which often already involves some understanding of their underlying nature. The first knowledge is only based on perceptual qualities and the sensorimotor skills used in the interaction with objects, whereas the second involves the representation of the imperceptible qualities, beliefs about how the object behaves, or, if it is animate, beliefs about which actions he is able to perform, in addition to giving us information about the kind of object that is being represented and its relationship with other things. See Jean MANDLER, "Perceptual and conceptual process in infancy," Jornal of Cognition and Development 1, (2000): 6-8, and QuinN, Paul, and Peter EIMAs, "A reexamination of the perceptual-to-conceptual shift in mental representations," Review of General Psychology 1, no. 3 (1997): 273. In any case, we can say that perceptual categories, heavily based on sensorimotor skills, are appropriate for explaining discrimination and recognition skills that children exhibit at an early age. These early skills normally do not compose. For example, a child can be able to recognize food and fish, but not fish food. See Daniel WEISKopF, "Observational Concepts," in The Conceptual Mind: New Directions in the Study of Concepts, ed. Eric Margolis, and Stephen Laurence (Massachusetts: MIT Press, 2015 ), 227-243.

44. Alva Nö, "Conceptual Pluralism, Direct Perception, and the Fragility of Presence," 2.

45. Alva Nö̈, Varieties of Presence (Massachusetts: Harvard University Press, 2012), 35.

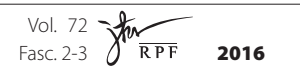

Provided for Personal License use. Not for reproduction, distribution, or commercial use. (C) 2016 Revista Portuguesa de Filosofia. All Rights Reserved. 
are not reduced or subordinated to just one type of access. Perceptual access, for example, does not have to be led or helped by the judgmental mode of understanding. Therefore, it would be inappropriate to assume that the structures involved to understand deliberate judgment-e.g. general representations-are more paradigmatic of what concepts are than the other structures involved in explaining the perceptual or active modes of access. As an access technique to keep us aware and in touch with what there is, sensorimotor skills meet all the necessary requirements, no less than judgment and thought. By way of illustration, in relation to a dog, we can access it and express understanding of its nature in different ways:

The idea that understanding a concept is mastery of a technique, a mastery that has multiple, distinct, context-sensitive ways of finding expression, helps here. One way to express understanding of dog is to talk and write about dogs. Another way is to be able to spot dogs on the basis of their appearance. Still another is to work or play comfortably with dogs. And the list goes on and on. We put our singular understanding of what dogs are to work in these different ways, and the understanding consists in the ability to do (more or less) all of that. ${ }^{46}$

Noë illustrates, in this order, the judgmental, perceptual, and active modes of understanding in relation to the dog. Returning to the discussion on the type of conceptualism Noë is committed to, it is now clear that he dispenses with the content view. The judgmental mode of understanding does not have to be generalized or extended to the other modes of understanding, such as the perceptual. Concepts in the perceptual mode of understanding place us in direct contact with things, but they are not general representations. The content of a perception is not a proposition. ${ }^{47}$ Can we say that he supports the state view? I believe so, but with some caveats. The statement, "You can't see the laser-projector if you don't know what a laser-projector is", ${ }^{48}$ would normally be an expression of commitment to state conceptualism: a subject cannot see $\mathrm{x}$ without possessing the concept of $\mathrm{x}$. However, we must emphasize that Noë, since his Varieties of Presence (2012), rejects that perceptual states are or involve representations, unlike in his earlier Action in Perception (2006), where his formulations remained protean in this respect. He now adopts a relational view of perception. ${ }^{49} \mathrm{In}$

46. Alva Nö, "Conceptual Pluralism, Direct Perception, and the Fragility of Presence," 11.

47. Ibid., 3 .

48. Ibid., 13.

49. Alva NoË, Varieties of Presence, 25. For a introduction to and a more deep discussion of

$$
\text { Vasc. } 22-3 \text { for } 2016
$$

Provided for Personal License use. Not for reproduction, distribution, or commercial use. (C) 2016 Revista Portuguesa de Filosofia. All Rights Reserved. 
this sense, his most recent position is not adjusted to the initial definition of state view. If we broaden this definition to incorporate dependence of perception on concepts, such as Noë understands them, then Noë is a state conceptualist in the sense that, to have a perceptual act in which the apple and its voluminous aspect are presented to us, we must have a skill of access, i.e., appropriate sensorimotor skills that allow us to maintain contact with the apple if one is in the field of vision. As he suggests, "Think of the concept in perception not as a category, or a representation, but a way of directly picking up what is there" 50 and "to say that perceptual experience is conceptual, from this standpoint, is to say that perceptual experience is a skillful grappling with what there is". ${ }^{51}$

Now, I am going to show how this approach to concepts and perception help us to explain the justificational role of perceptual experience. When discussing the distinct modes of access and understanding, Noë forgoes the inferential relations between experience and thought that McDowell explored in Mind and World. Without them, we aggravate the problem of interface, or we no longer have an explanation for how the second requirement of the shared content thesis is satisfied.

\section{The justificational role of sensorimotor skills}

Initially, we can observe that the first requirement of the shared content thesis is easily satisfied by Noë's actionist theory of perception and his conception of concepts as skills of access. What we access directly through the perceptual mode of understanding can be equally accessed by the judgmental mode of understanding. The reverse need not be true, since we can access abstract or non-observable entities through the judgmental mode of understanding, but not through the perceptual mode of understanding. For our purposes, it is sufficient that part of empirical thought can be directly and rationally constrained by experience. These skills of access, by putting us in touch with what there is, express, through the peculiar way that each of them establishes and maintains this contact, an understanding of the nature of what exists. We will further discuss this understanding later, but it is important to keep in mind that we

the relational view, see John CAmpBell, Reference and Consciousness (New York: Oxford University Press, 2002), 114-131.

50. Alva Nö̈, "Conceptual Pluralism, Direct Perception, and the Fragility of Presence," 11.

51. Alva NoË, Varieties of Presence, 35.

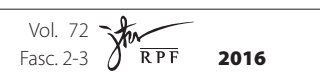

Provided for Personal License use. Not for reproduction, distribution, or commercial use. (C) 2016 Revista Portuguesa de Filosofia. All Rights Reserved. 
have already left behind the view that something has been given to us in experience or in thought in a purely passive manner. I dispense with the "myth of the given" as much as do Sellars and McDowell. According to the actionist theory of perception, having something present through perception or thought is a cognitive achievement; it is the result of the exercise of a skill of access.

The independence thesis is also vindicated by Noë's actionist theory of perception. The sensorimotor skills do not seem to be cognitively penetrated by beliefs, since the conceptual and inferential connections that pose a threat to McDowell's position in Mind and World are not present in Noë's position. The sensorimotor skills are not cognitively penetrated, even by other sensorimotor skills, since they do not enter into compositional relations. However, someone could claim that sensorimotor skills, since they are learned and flexible-i.e., sensitive to new situations-are cognitively penetrated. This point needs to be examined. The learning and fine tuning of sensorimotor skills depends more on interaction with the environment than the background knowledge that the subject already has. In fact, since they constitutively involve a very fine-tuned adjustment between the repertoire of body actions that the subject is able to perform and the presence of a certain kind of object in the surroundings, sensorimotor skills result much more from the continuous and systematic interaction with this kind of object than from beliefs and other superior cognition that can indirectly support or guide the acquisition of these skills. The possession of a skill depends constitutively on success. Just like an archer's apprentice does not have the skill to launch an arrow into the bullseye while repeatedly missing the mark by far, even in favorable environmental conditions, we also do not learn to see the voluminous aspect of the apple or the circularity of the plate as long as we are unable to grasp, hold, follow, or track the apple or plate in our field of vision with relative success. A skill is a disposition or a set of dispositions that results in success if exercised in suitable conditions. The case of sensorimotor skills is no different. Therefore, even though there can be indirect cognitive influence on the learning of a cognitive skill, it is irrelevant to the independence thesis. Having a sensorimotor skill for accessing apples means that, when it is exercised in the appropriate conditions, the subject directly sees the apple that is in her vision field and its voluminous aspect. The apple itself and its voluminous aspect are present for the subject through her experience. It is not a representation that could or could not be correct, which, then, would threaten the independence thesis. As techniques for access, sensorimotor skills, once acquired, reliably place us in direct contact with the

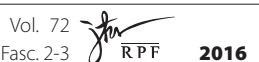

Provided for Personal License use. Not for reproduction, distribution, or commercial use. (C) 2016 Revista Portuguesa de Filosofia. All Rights Reserved. 
surrounding environment. Thus, we can conclude that, even though there could be some cognitive influences on the acquisition of these skills, the result of the exercise of a sensorimotor skill in appropriate conditions, because it is not a representation, is not itself cognitively penetrated. The independence claim is thus guaranteed. As we stated above, what it requires is that perceptual experience presents the world as it really is.

What remains to be explained now is how the second requirement of the shared content thesis is satisfied. The surrounding world is presented to us intelligibly through perception, i.e., manifesting a type of understanding of the world; but the world is not, through perception, presented propositionally. The judgmental mode of understanding presents the world to us, the same world, propositionally. However, how can the subject recognize the relevance of what is perceptually presented to her to what she thinks about the world when she entertains a proposition? In principle, we could be led to think that these modes of access, since they are different-i.e., not reducible to one another-do not maintain any type of rational relationship between each other. If this were the case, the problem of the interface would seem unsolvable. It is not quite so, as I will now seek to show.

First, the recognition of a truth-indicating relationship is not exemplified by thoughts only. It is true that if $p$ implies $q$, the recognition of the relevance of $p$ for the truth of $q$ is exemplified by the occurring belief that $p$ implies $q$. However, this recognition could also be manifested by the individual's inferential practice of extracting $q$ whenever authorized to assume $p$ or to believe $p$. The ability to explicitly represent this relationship of implication is not necessary for possessing the skill of identifying and being sensitive to this relationship. In fact, for reasons similar to those presented by Ryle for the priority of knowing-how in relation to knowing-that ${ }^{52}$, it seems much more reasonable that the belief that $p$ implies $q$ can only be legitimately attributed to a subject if the subject is capable of responding appropriately to instances of the implication relationship at issue in different inferential contexts. Thus, the exercise of the ability to identify the relationship of implication between $p$ and $q$ is enough to manifest the recognition of the relevance of $p$ for the truth of $q$. We have not yet addressed the interface problem, since, in the case at hand, we are dealing with the recognition of the logical or conceptual relationships

52. See Gilbert Ryle, "Knowing How and Knowing That," Proceedings of the Aristotelian Society 46, (1945): 1-16.

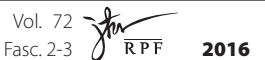

Provided for Personal License use. Not for reproduction, distribution, or commercial use. (C) 2016 Revista Portuguesa de Filosofia. All Rights Reserved. 
between propositions. Nevertheless, I propose to dispense with the explicit deliberation as a necessary condition for the recognition of a truth-indicating relationship. In other words, the exercise of skills can be sufficient for explaining how an individual's mental state can provide a reason for believing. In the case at hand, the ability to recognize that $p$ implies $q$, when exercised correctly, gives the subject a reason to believe in $q$ given $p$.

The acquisition of a sensorimotor repertoire of skills that is broad enough to make us capable of accessing and exploring the surrounding world provides what I propose to call the space of actions or affordances, ${ }^{53}$ in contrast to the Sellars's logical space of reasons. A subject in possession of sensorimotor skills is in a world structured by the possibility of actions in which the subject moves to carry out her needs. If I am walking in a muddy area and I want to avoid the mud at all costs, some parts of the ground will be seen as firmer than others, not in the sense that I classify them as being "firm," but rather in the sense that I prepare for or am willing to step on these parts. If I am tired and seeking a place to rest, a wooden stump in the area will invite me to rest upon it. The set of possibilities for actions or affordances that an object offers in relation to the individual's skills constitutes the perceptual understanding that she has of this object. This understanding mediates the way that the object is perceptually presented. The object is not simply given to us; it is presented as being a certain way, i.e., as being an object that requests or allows a series of affordances. This understanding is still not propositional, but it is rich enough for us to say that the object and its properties are, to the individual with the appropriate sensorimotor skills, situated in the space of actions.

The capacity to situate an object in the space of actions implies having a kind of understanding of the nature of this object, which is not propositional. For example, the sensorimotor skills by which we access an apple in the environment does not by itself give us propositional knowledge that the apple in the field of vision is red. Nevertheless, it can be claimed that those sensorimotor skills, when exercised in the appropriated conditions,

53. The technical term "affordance" was introduced by James Gibson and designates a relationship between the organism and the environment; "the affordances of the environment are what it offers the animal, what it provides or furnishes, either for good or ill", depending on the skills of the animal and its body features. Certain protuberances on a hill help a professional climber, who will be able to apply the necessary push on them to climb, but they are of no use to a beginner. Some surfacesfor example, the surface of a lake-do not afford human walking but do afford the ambulation of some insects. See James GiBson, The Ecological Approach to Visual Perception: Classic Edition (New York: Taylor and Francis Group, 2015), 119.

$$
\text { Vol. } 72 \text { Fasc. } 2-3 \text { tor } 2016
$$

Provided for Personal License use. Not for reproduction, distribution, or commercial use. (C) 2016 Revista Portuguesa de Filosofia. All Rights Reserved. 
give us direct access to the apple and some understanding of the nature of the apple. This understanding is manifested in the repertory of bodily actions that the subject is able to exercise in relation to the apple and in the set of tasks that the subject is able to accomplish in which this kind of object is involved. In order to have this kind of perceptual understanding, it is not necessary that the subject be able to understand those bodily actions and those tasks through the judgmental mode of understanding. It is enough that the subject possesses the appropriate sensorimotor skills and exercises them in the appropriate conditions. I agree with Sellars that a red sensation does not give us the non-inferential knowledge that something is red. However, the appropriate sensorimotor skills give us direct access to red objects in the environment and an understanding of their nature. This understanding is manifested, for example, in the exercise of sensorimotor skills through which we track red objects even in the conditions of illumination variation or in that exercise through which we discriminate red objects from blue ones.

Direct access to the objects in the environment and the space of actions in which we intelligibly situate these objects serve as a gateway for introducing observational concepts, now understood in the judgmental mode of understanding, i.e., as general representations. Observational concepts, according to Daniel Weiskopf, "are those that are spontaneously made available at the interface between perception-action systems and the conceptual system", ${ }^{54}$ or, to use Noë's terminology, at the interface between understanding in the perceptual mode and in the judgmental mode..$^{55}$ The observational concepts are causally connected to the perceptual states, i.e., they are normally caused by exercising the sensorimotor skills. One type of perceptual state resulting from the exercise of certain sensorimotor skills-for example, those that enable us to access the apple-is associated with the symbol APPLE. Since the observational concepts are also a skill, the perceptual state, for example, the access to the apple, does not invariably cause the occurrence of the corresponding observational concept. The application of the concept depends on other relative conditions related to the subject's attention, motivation, and thoughts that she

54. Daniel WeISKOPF, "Observational Concepts," 223.

55. The idea that possessing observational concepts that meet Evans's generalization condition must be explained by perceptual discrimination skills that do not involve general representations themselves, in this sense, can also be found in Bermúdez. See José Bermúdez, "What is at stake in the debate on nonconceptual content?," Philosophical Perspectives 21, (2007): 55-72.

$$
\text { Fol. } 72 \text { Fasc. } 2-3 \text { for } 2016
$$

Provided for Personal License use. Not for reproduction, distribution, or commercial use. (C) 2016 Revista Portuguesa de Filosofia. All Rights Reserved. 
may be entertaining. Thus, we can perceptually access an apple without classifying it as such by means of an observational concept, and we can think about an apple through the observational concept APPLE without accessing it perceptually. Essentially, these concepts fulfill two functions: (a) they make it possible to think about an object when it is no longer accessible through the perceptual mode, and (b) they also make it possible to extend our understanding on the nature of the object by allowing us to place it in relation to other objects and properties that are also inaccessible through the perceptual mode. These two functions are related to the characteristic of generality that are not available in the perceptual mode. The ability to access an object through the perceptual mode is highly dependent on context. Thus, the token APPLE could be triggered, even in the absence of its associated perceptual state, and can be used to relate the apple to other things beyond the bodily actions that, in the perceptual mode, would be available to establish and maintain perceptual access to the apple.

Learning an observational concept ${ }^{56}$ is highly dependent on the perceptual mode of understanding, since the paradigmatic cases for its applicability are the objects accessed perceptually by means of the sensorimotor skills with which the concepts is causally associated. Observational concepts are thus introduced; they would not be observational if they did not have this strong restriction on their application. The rational relationship between a perceptual state and a thought is not, in fact, inferential or quasi-inferential. It is a substantial relationship, since the object accessed perceptually is what makes the application of the corresponding observational concept correct, in a great number of cases and fundamentally in the paradigmatic ones. The identity of an observational concept is given in part by the sensorimotor skills with which it is associated; in this sense, the association between sensorimotor skills and observational concepts are of a constitutive nature. Thus, the perception of an apple serves as a reason for the belief of the subject that there is an apple in the field of vision, to the extent that when applying the APPLE concept to think about the object that she accesses perceptually, she exercises a skill whose acquisition involved taking that kind of object to be paradigmatic

56. The discussion about what is and what is not observational is important if we want to answer the question of how directly empirical thought as a whole can be rationally constrained by experience; however, in this article, I only aim at the more modest issue of suggesting how this rational constraint is possible. For more on this debate, see Daniel WeISKOPF, “Observational Concepts," 229-233.

$$
\text { Fasc. } 22-3 \text { for }
$$

Provided for Personal License use. Not for reproduction, distribution, or commercial use. (C) 2016 Revista Portuguesa de Filosofia. All Rights Reserved. 
for the application of this concept. Acquiring an observational concept involves assimilating the commitment to treating a certain kind of object or property, accessible through the perceptual mode of understanding, as paradigmatic for its application. The recognition of the rational relationship between the perception of an object and the belief in which the observational concept of this object figures does not need to involve the thought that this object is an instance of this concept; the fact that the concept at issue has been adequately exercised is sufficient, i.e., in response to the perceptual access to an object of the kind with which the concept is associated. As we have already argued, the exercise of a skill can be enough to explain the recognition of a truth-indicating relationship. This relationship is not, at the interface between perception and empirical thought, instantiated by an inferential or quasi-inferential relationship, as McDowell thought of in Mind and World, but rather by a substantial relationship; i.e., the content of our thought is satisfied by what is presented to us perceptually, and the recognition of this relationship expresses itself in the very exercise of the observational concept which figures in thought.

\section{Concluding remarks}

Empirical thought is constrained by perceptual experience not in virtue of its propositional content, that would hold inferential relations with empirical beliefs, but mainly in virtue of the fact that perceptual experience gives us direct access to objects and properties that satisfy observational concepts introduced and learned in strong connection with the space of actions. When these concepts are applied in the formation or maintenance of a judgment in response to the appropriate perceptual experience, the exercise of the conceptual skill in question manifests the recognition that the objects accessed through this experience satisfy the observational concepts which figure in the judgment. The internalism defended is minimal, since it is not required that the subject be able to elaborate this recognition in the judgmental mode of understanding. So, we can be internalists without being intellectualists. The shared content thesis does not require the content conceptualism and can be reconciled with the claim that perception is independent from belief. The latter claim, in its turn, is compatible with the influence of belief on learning sensorimotor skills to the extend that the result from the exercise of those skills in the appropriate conditions could be taken as implying a direct access to surrounding objects and their properties. In this paper, the actionist

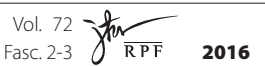

Provided for Personal License use. Not for reproduction, distribution, or commercial use. (C) 2016 Revista Portuguesa de Filosofia. All Rights Reserved. 
theory of perception was not defended from empirical and conceptual objections.$^{57}$ I have assumed its plausibility in order to elaborate an explanation for the justificational role of perceptual experience.

\section{References}

Bermúdez, José. "What is at stake in the debate on nonconceptual content?" Philosophical Perspectives 21, (2007): 55-72.

CAmP, Elizabeth. "A language of baboon thought." In The Philosophy of Animal Minds, edited by Robert Lurz, 108-127. New York: Cambridge University Press, 2009.

CampBell, John. Reference and Consciousness. New York: Oxford University Press, 2002.

Evans, Gareth. The Varieties of Reference. Oxford: Clarendon Press, 1982.

FoDor, Jery. "Burge on perception." In The Conceptual Mind: New Directions in the Study of Concepts, edited by Eric Margolis, and Stephen Laurence, 203-222. Massachusetts: MIT Press, 2015

Gibson, James. The Ecological Approach to Visual Perception: Classical Edition. New York: Taylor and Francis Group, 2015.

Heck, Richard. "Nonconceptual content and the space of reasons." The Philosophical Review 109, (2000): 483-523.

Hutto, Daniel and Erick Myin. Radicalizing Enactivism: Basic Minds without Content. Cambridge, MA: MIT Press, 2013.

MANDLER, Jean. "Perceptual and conceptual process in infancy." Journal of Cognition and Development 1, no. 1 (2000): 3-36.

McDowelL, John. Mind and World. Massachusetts: Harvard University Press, 1996.

McDowell, John. "Avoiding the myth of the given." In Having the World in View, 256-274. Massachusetts: Harvard University Press, 2013.

MuRPhy, Gregory. The Big Book of Concepts. Massachusetts: MIT Press, 2004.

NanaY, Bence. "Empirical Problems with Anti-Representationalism." In Does Perception Have Content?, edited by Berit Brogaard, 39-50. New York: Oxford University Press, 2014.

Nö̈, Alva. Action in Perception. Massachusetts: MIT Press, 2006.

NoË, Alva. Varieties of Presence. Massachusetts: Harvard University Press, 2012.

NoË, Alva. "Conceptual Pluralism, Direct Perception, and the Fragility of Presence." In Open MIND: 27(T), edited by Thomas Metzinger, and Jennifer Windt, 1-15. Frankfurt am Main: MIND Group, 2015. DOI 10.15502/9783958570597.

Pylyshyn, Zenon. Seeing and Visualizing: It's Not What You Think. Massachusetts: MIT Press, 2003.

QuinN, Paul, and Peter Eimas. "A reexamination of the perceptual-to-conceptual shift in mental representations.” Review of General Psychology 1, no. 3 (1997): 271-287, 1997.

Raftopoulos, Athanassios. "The cognitive impenetrability of perception and theory-ladenness." Journal for General Philosophy of Science 46, (2015): 87-103.

Ryle, Gilbert. "Knowing how and knowing that." Proceedings of the Aristotelian Society 46,

57. See Bence NanaY, "Empirical Problems with Anti-Representationalism," in Does Perception Have Content?, ed. Berit Brogaard (New York: Oxford University Press, 2014), 39-50

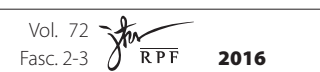

Provided for Personal License use. Not for reproduction, distribution, or commercial use. (C) 2016 Revista Portuguesa de Filosofia. All Rights Reserved. 


\section{Author's Personal Copy}

An Actionist Approach to the Justificational role of Perceptual Experience

(1945): 1-16.

Sellars, Wilfrid. Science, Perception and Reality. London: Routledge \& Kegan Paul, 1963.

Siegel, Susan. "Cognitive penetrability and perceptual justification." Noûs 46, no. 2 (2012): 201-222.

Stalnaker, Robert. "What might nonconceptual content be?” Philosophical Issues 9, (1998): 339-352.

WeIskopf, Daniel. "Observational concepts." In The Conceptual Mind: New Directions in the Study of Concepts, edited by Eric Margolis, and Stephen Laurence, 227-234. Massachusetts: MIT Press, 2015. 
Author's Personal Copy 